\title{
Andreas Flurschütz da Cruz, Zwischen Füchsen und Wölfen. Konfession, Klientel und Konflikte in der fränkischen Reichsritterschaft nach dem Westfälischen Frieden
}

Falk Bretschneider

\section{(2) OpenEdition}

Journals

Édition électronique

URL : http://journals.openedition.org/ifha/11011

DOI : 10.4000/ifha. 11011

ISSN : 2198-8943

Éditeur

IFRA - Institut franco-allemand (sciences historiques et sociales)

Référence électronique

Falk Bretschneider, «Andreas Flurschütz da Cruz, Zwischen Füchsen und Wölfen. Konfession, Klientel und Konflikte in der fränkischen Reichsritterschaft nach dem Westfälischen Frieden », Revue de l'IFHA [En ligne], Date de recension, mis en ligne le 22 septembre 2020, consulté le 23 septembre 2020. URL: http://journals.openedition.org/ifha/11011 ; DOl : https://doi.org/10.4000/ifha.11011

Ce document a été généré automatiquement le 23 septembre 2020.

(C)IFHA 


\title{
Andreas Flurschütz da Cruz, Zwischen Füchsen und Wölfen. Konfession, Klientel und Konflikte in der fränkischen Reichsritterschaft nach dem Westfälischen Frieden
}

\author{
Falk Bretschneider
}

«Renards contre loups » - ce n'est pas un jeu d'enfant, mais l'histoire d'un conflit entre deux familles importantes de la chevalerie immédiate, les Fuchs von Bimbach et les Wolf von Wolfsthal, toutes deux membres du canton de Baunach (cercle chevaleresque de Franconie). Entre 1650 et 1701, elles se disputent deux villages, Westheim et Eschenau, situés entre Bamberg et Wurtzbourg, cristallisant ainsi un ensemble de tensions juridiques, sociales, économiques et confessionnelles qui traversent alors la basse noblesse du Saint-Empire. L'histoire est complexe et touffue. Elle débute avec deux cédules établies par un membre de la famille des Fuchs pour reconnaître des dettes contractées suite à un mariage en

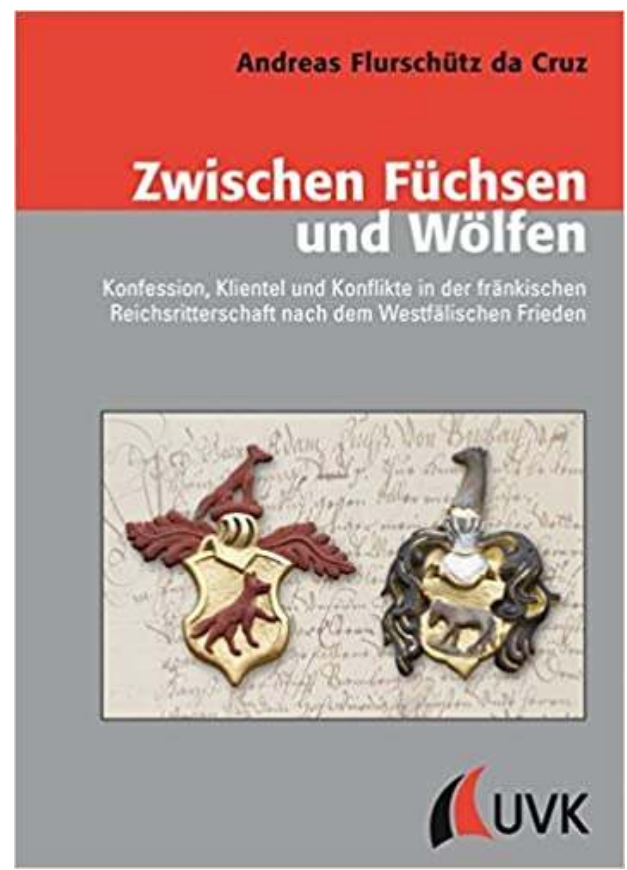
1620. Les héritiers de leurs propriétaires initiaux les vendent quelques décennies plus tard aux Wolf qui les utilisent pour fonder leurs revendications sur les deux villages, jusque-là en possession des Fuchs. Affaiblis par l'extinction de plusieurs 
branches du lignage et par de grandes difficultés économiques, ces derniers subissent en 1650/1651 le transfert de leur fief aux Wolf qui à cette occasion tirent avantage de leurs bonnes relations avec le prince-évêque de Bamberg dans l'administration duquel ils servent. S'ensuivent 50 ans de bataille juridique, d'abord devant des instances locales (la cour féodale de Bamberg), puis, à partir de 1692, devant le Conseil impérial aulique (Reichshofrat) à Vienne. Finalement, en 1700, les Fuchs sont rétablis dans leur fief, après avoir payé leurs dettes et réussi à retourner les rapports de pouvoir initialement favorables aux Wolf et à leurs protecteurs, les princes-évêques issus de la famille Schönborn.

Ce qui ressemble, de prime abord, à une simple rivalité sur fond de querelle financière entre deux familles chevaleresques autour de quelques villages perdus dans les forêts franconiennes s'avère, au prisme de l'analyse menée par A. F. d. C., une fascinante histoire dans laquelle se reflètent les structures générales de la société de l'Empire post-westphalien et le jeu multiscalaire de la politique impériale, mais aussi plusieurs transformations qui touchent plus particulièrement les membres de la chevalerie immédiate: le déclin économique de la plupart des familles chevaleresques franconiennes, sous forte pression financière depuis le XVIe siècle; leur implication dans l'opposition entre protestants et catholiques qui structure la société du SaintEmpire pendant toute l'époque moderne et crée notamment en Franconie un dense lacis de " sociétés frontalières » confessionnelles entre les terres chevaleresques (plutôt dominées par le luthéranisme) et les territoires des princes-évêques (qui sont restés catholiques) ; la judiciarisation de la conflictualité depuis l'interdiction de la faide au XVesiècle et le transfert contraint des litiges devant la justice impériale; la nécessité pour les chevaliers, afin de faire face aux défis économiques et politiques auxquels ils sont confrontés, de trouver des moyens financiers et des soutiens, notamment en jouant la carte des réseaux de patronage et du clientélisme régional ou en profitant de l'opposition entre les deux princes ecclésiastiques de Wurtzbourg et Bamberg (qui euxmêmes utilisent le conflit afin d'améliorer leur position dans la lutte pour la domination régionale); enfin, les efforts des chevaliers pour assurer non seulement la survie de leurs familles mais aussi leur procurer une ascension sociale, au prix de la conversion au catholicisme (1692 pour les Wolf, 1707 pour les Fuchs), par l'attachement à la cour impériale ou l'entrée dans les institutions impériales (en 1706, les Fuchs et les Wolf sont élevés au rang de comtes d'Empire et des membres de leurs familles reçus comme assesseurs au Conseil impérial aulique).

Issu d'une thèse de doctorat soutenue en 2013 à l'université de Bamberg, l'ouvrage se démarque par un style clair qui réussit à présenter une matière extrêmement complexe de manière compréhensible et structurée. En outre, il ne se contente pas de retracer l'histoire des deux familles adversaires et les étapes du conflit (les documents sur ce dernier ayant en grande partie disparu, l'analyse doit se fonder sur des matériaux divers provenant de quinze dépôts d'archives, publics et privés), mais inscrit celui-ci dans une étude plus large sur les usages sociaux du judiciaire et les interdépendances au sein même du groupe de la noblesse chevaleresque (rapports matrimoniaux, alliances politiques, oppositions confessionnelles...) et avec d'autres groupes d'acteurs de la société impériale (la cour de Vienne, la noblesse autrichienne, les cours et les administrations des deux princes-évêques de Bamberg et Wurtzbourg, eux-mêmes souvent issus de la chevalerie immédiate). Au total donc un travail très instructif dont l'érudition est attestée par 2601 notes de bas de page qui ne contiennent pas seulement les renvois aux archives et références bibliographiques, mais discutent souvent de 
problèmes annexes. Dans une étude qui insiste sur les relations familiales et les jeux politiques et sociaux des chevaliers l'on s'étonne juste de l'absence, dans la bibliographie, de l'étude importante de C. Duhamelle sur les stratégies matrimoniales de la chevalerie rhénane (1998), en partie consacrée aux mêmes questions que celles posées par l'auteur.

INDEX

Thèmes : Histoire sociale

Index chronologique : Époque moderne

\section{AUTEURS}

\section{FALK BRETSCHNEIDER}

EHESS Paris 